\title{
COMPARISON OF HAEMODYNAMIC EFFECTS AND EASE OF I-GEL INSERTION WITH DEXMEDETOMIDINE-PROPOFOL VS. FENTANYL-PROPOFOL
}

\author{
Priyanka Dabas ${ }^{1}$, Jitesh M. Rasquinha², Keerthi Puttige3, Ashirwad Dubey ${ }^{4}$
}

${ }_{1}^{1}$ Postgraduate Student, Department of Anaesthesiology, Kasturba Medical College, Mangalore.

${ }^{2}$ Associate Professor, Department of Anaesthesiology, Kasturba Medical College, Mangalore.

${ }^{3}$ Postgraduate Student, Department of Anaesthesiology, Kasturba Medical College, Mangalore.

4 Postgraduate Student, Department of Anaesthesiology, Kasturba Medical College, Mangalore.

\section{ABSTRACT}

\section{BACKGROUND}

In search of an optimal drug for I-gel insertion, in our study, we have compared two group of drugs dexmedetomidine with propofol and fentanyl with propofol.

\section{MATERIALS AND METHODS}

The study design used is a prospective randomised double blind study. 80 ASA I and II adult patients were divided into two groups: Group 'A' (to whom $1 \mathrm{mcg} / \mathrm{kg}$ dexmedetomidine and propofol given) with 40 patients and Group 'B' (to whom $1 \mathrm{mcg} / \mathrm{kg}$ fentanyl and propofol is given) with 40 patients in each group. For induction, propofol $2 \mathrm{mg} / \mathrm{kg}$ was given IV and 90 seconds later I-gel was inserted. We have observed heart rate, respiratory rate, noninvasive blood pressure and oxygen saturation before induction; 30 seconds after induction; 1, 3, 5, 10 and 15 minutes after insertion of I-gel. Patient's response to I-gel insertion like coughing, gagging or any movement were noted. Statistical analysis of data was done using student $t$ test for parametric data, Chi-square test for nonparametric data and SPSS 17.0 for windows software.

\section{RESULTS}

The baseline mean HR showed no statistically significant difference in both the groups. Postinduction after 15 min. of I-gel insertion, statistically significant difference noted in group A ( $\mathrm{p}=0.001)$. Baseline recordings of NIBP were similar in both the groups, whereas recordings after premedication till $10 \mathrm{~min}$. after induction post I-gel insertion showed a significant difference $(\mathrm{p}<0.01)$. The MAP was significantly lower in group A. However, at end of 15 min., fall in MAP was similar ( $p=0.092)$. $p=0.5$, no statistically significant difference was observed in no. of attempts required, airway manipulation and adverse effects.

\section{CONCLUSIONS}

Both dexmedetomidine and fentanyl with propofol provides ideal conditions for I-gel insertion with more attenuation of haemodynamic response in dexmedetomidine group compared to fentanyl group.

\section{KEYWORDS}

Dexmedetomidine, Ease of Insertion, Propofol, Fentanyl.

HOW TO CITE THIS ARTICLE: Dabas P, Rasquinha JM, Puttige K, et al. Comparison of haemodynamic effects and ease of I-gel insertion with dexmedetomidine-propofol vs. fentanyl-propofol. J. Evolution Med. Dent. Sci. 2016;5(102):7450-7454, D0I: 10.14260/Jemds/2016/1687

\section{BACKGROUND}

Laryngoscopy and endotracheal intubation produce reflex sympathetic stimulation and are associated with raised levels of plasma catecholamines, hypertension, tachycardia, myocardial ischaemia, depression of myocardial contractility, ventricular arrhythmias and intracranial hypertension ${ }^{1}$. The wide variety of airway devices available today may broadly be classified as intraglottic and extraglottic airway devices, which are employed to protect the airway in both elective as well as emergency situations. ${ }^{2}$

To overcome the limitations of currently available supraglottic airway devices like LMA-ProSeal (e.g. high cost,

Financial or Other, Competing Interest: None.

Submission 15-11-2016, Peer Review 09-12-2016,

Acceptance 15-12-2016, Published 22-12-2016.

Corresponding Author:

Dr. Jitesh M. Rasquinha,

Flat No. G01, Fatima Garden,

Old Kent Road,

Mangalore- 575001.

E-mail:dr_jitesh@yahoo.co.in

DOI: $10.14260 /$ jemds $/ 2016 / 1687$

\section{(c) $(\mathbf{P})$}

demand for careful handling to prevent cuff damage and relative difficulty of insertion) a new and cheaper supraglottic airway device "I-gel" (Intersurgical Ltd., Wokingham, Berkshire, UK) has been developed. I-gel insertion requires adequate mouth opening, minimal upper airway reflexes such as coughing, gagging or laryngospasm. ${ }^{3}$

As propofol itself does not have any analgesic property, opioids are added which reduce the effective concentration ( $\mathrm{EC}_{50}$ LMA) for I-gel insertion of propofol for various noxious stimuli with minimal respiratory depression and without high BIS value. ${ }^{4}$ Here, fentanyl is the opioid of choice.

In this study, we intend to provide successful I-gel insertion conditions by using dexmedetomidine with propofol and to compare its effect with fentanyl combined with Propofol.

\section{Aim}

To compare easiness of insertion of I-gel, haemodynamic effects with 2 adjuvant drugs, dexmedetomidine and fentanyl, when used with induction agent propofol. 


\section{Objectives}

1. To compare ease of insertion of I-gel with dexmedetomidine-propofol and fentanyl-propofol.

2. To compare the adverse effects following I-gel insertion with dexmedetomidine-propofol and fentanyl-propofol.

\section{MATERIALS AND METHODS}

\section{Study Design}

The study design used is a prospective randomised double blind study.

\section{Study Setting}

The Study was done in the following Hospitals

1. KMC Hospital , Ambedkar circle, Mangalore.

2. KMC Hospital, Attavar, Mangalore.

\section{Study Population}

The study was carried out in 80 adult patients of age group (18-50 yrs.) of physical status ASA I \& II scheduled to undergo elective surgical procedures.

\section{Sample Size}

The study was carried out in 80 adult patients who are divided into two groups.

\section{Inclusion Criteria}

1. ASA grade I \& II.

2. 18-50 years of age.

3. Mallampati class I and II.

4. Patients scheduled to undergo elective surgical procedures.

\section{Exclusion Criteria}

1. Emergency surgery with risk of gastric aspiration.

2. Patients who refuse for the study or have any known allergy.

3. Patients undergoing oral surgeries with difficult airway.

4. Those with Hepatic/Renal/cardiopulmonary abnormality, bleeding diathesis.

5. ASA grade III \& IV patients

6. Mallampati grade III \& IV.

Pregnant and paediatric patients and patients with BMI $>25$. A written and informed consent was taken after the Institutional Ethics Committee's and the Scientific Committee's approval is taken for the study.

\section{Randomisation}

The randomisation method used for the study is Block Randomisation.

\section{Methodology}

After the approval from the Ethics Committee, 80 consenting patients fulfilling the inclusion criteria were considered for our study.

All patients were clinically examined during pre-operative evaluation and whole procedure was explained. Basic investigations were done.

Group A: Receiving dexmedetomidine-propofol $1 \mathrm{mcg} / \mathrm{kg}$ diluted in $10 \mathrm{~mL}$ normal saline of dexmedetomidine and 2 $\mathrm{mg} / \mathrm{kg}$ of propofol for induction without neuromuscular blocking agents.

Group B: Patients receiving fentanyl-propofol $1 \mathrm{mcg} / \mathrm{kg}$ of fentanyl and $2 \mathrm{mg} / \mathrm{kg}$ of propofol.

Once the patient is shifted into the operating theatre, standard intra-operative monitoring is done using ECG, Pulse oxymeter, NIBP/Mean Arterial Pressure.

Patient preoxygenation with $8 \mathrm{~L} / \mathrm{min}$. of oxygen for $3 \mathrm{~min}$. In Group B, $1 \mu \mathrm{g} / \mathrm{kg}$ fentanyl was given over $2 \mathrm{~min}$. In Group A, $1 \mu \mathrm{g} / \mathrm{kg}$ dexmedetomidine diluted in $10 \mathrm{~mL}$ NS was given over $2 \mathrm{~min}$. After $30 \mathrm{sec}$., inj. propofol $2 \mathrm{mg} / \mathrm{kg}$ was administered to both the groups. Anaesthesia was maintained by $50 \%$ nitrous oxide and oxygen and $1.5 \%$ sevoflurane, after adequate response I-gel of appropriate size was inserted.

The I-gel supraglottic airway device then connected to the breathing circuit.

\section{RESULTS}

Present study included 80 patients of either sex undergoing elective gynaecological, orthopaedics or general surgery procedures.

The insertion of the I-gel with propofol-dexmedetomidine and with propofol-fentanyl were evaluated.

There was no significant difference between the two groups with respect to age, weight, sex distribution, ASA grades.

\section{I-Gel Insertion Attempts}

I-gel was successfully inserted in one or two attempts in all the patients. No patients required muscle relaxation to aid I-gel insertion.

The success rate at first attempt of insertion was $82.5 \%$ in group A and $92.5 \%$ in group B respectively.

In $17.5 \%$ patients in group A, $7.5 \%$ in group B, I-gel was inserted in second attempt.

No statistically significant difference noted in number of attempts required for I-gel insertion in both the groups. $(\mathrm{p}=0.5)$.

\section{Response to I-Gel insertion}

The patient response to I-gel insertion was excellent (100\%) in both the groups.

Statistically no significant difference was found. ( $p=1.00)$.

\section{Airway Manipulation Required for I-Gel Insertion}

Statistically no significant difference noted in both A and B groups with respect to jaw thrust, chin lift, increasing depth of anaesthesia and changing device.

Adequate chest expansion and ventilation was achieved in $100 \%$ patients in both the groups.

Leak was observed in 5\% in group A and 5\% in group B. And stridor was absent in both the groups. Statistically no significant difference noted.

- I-gel insertion grading by an anaesthesiologist.

- I-gel insertion was easy in both the groups.

\section{Mean Arterial Pressure}

Baseline recordings were similar in both the groups, whereas recordings after premedication till $10 \mathrm{~min}$. after induction post I-gel insertion showed a significant difference $(\mathrm{p}<0.01)$. The 
MAP was significantly lower in group A. However, at the end of 15 min. fall in MAP was similar $(p=0.092)$.

\section{Change in Mean Heart Rate}

The baseline mean HR showed no statistically significant difference in both the groups. Post induction after $15 \mathrm{~min}$. of Igel insertion statistically significant difference noted in group $A(p=0.001)$. Fall in mean heart rate was more in group A compared to group B.

\begin{tabular}{|c|c|c|c|c|}
\hline \multicolumn{5}{|c|}{ Attempts *Group Cross tabulation } \\
\hline & & \multicolumn{2}{|c|}{ Group } & \multirow[b]{2}{*}{ Total } \\
\hline & & $\begin{array}{c}\text { Group } \\
\text { A }\end{array}$ & $\begin{array}{c}\text { Group } \\
\text { B }\end{array}$ & \\
\hline \multirow[t]{2}{*}{ Attempts } & $\begin{array}{c}\text { Count } \\
\text { \% within } \\
\text { Group }\end{array}$ & $\begin{array}{c}33 \\
82.5 \%\end{array}$ & $\begin{array}{c}37 \\
92.5 \%\end{array}$ & $\begin{array}{c}70 \\
87.5 \%\end{array}$ \\
\hline & Count & $\begin{array}{c}7 \\
17.5 \%\end{array}$ & $\begin{array}{c}3 \\
7.5 \%\end{array}$ & $\begin{array}{c}10 \\
12.5 \%\end{array}$ \\
\hline
\end{tabular}

\begin{tabular}{|c|c|c|c|c|}
\hline & $\begin{array}{c}\text { \% within } \\
\text { Group }\end{array}$ & & & \\
\hline Total & $\begin{array}{c}\text { Count } \\
\text { \% within } \\
\text { Group }\end{array}$ & $\begin{array}{c}\mathbf{4 0} \\
\mathbf{1 0 0 . 0} \%\end{array}$ & $\begin{array}{c}\mathbf{4 0} \\
\mathbf{1 0 0 . 0} \%\end{array}$ & $\begin{array}{c}\mathbf{8 0} \\
\mathbf{1 0 0 . 0} \%\end{array}$ \\
\hline \multicolumn{4}{|c|}{ Table 1. I-Gel Insertion Attempts } \\
\hline
\end{tabular}

\begin{tabular}{|c|c|c|c|c|}
\hline & \multicolumn{2}{|c|}{ Group } & \multirow{2}{*}{ Total } \\
\hline & & Group A & Group B & \\
\hline \multirow{4}{*}{$\begin{array}{l}\text { Rating of } \\
\text { I-gel } \\
\text { insertion }\end{array}$} & \multirow{2}{*}{ Easy } & 39 & 39 & 78 \\
\hline & & $97.5 \%$ & $97.5 \%$ & $97.5 \%$ \\
\hline & \multirow{2}{*}{ V. Easy } & 1 & 1 & 2 \\
\hline & & $2.5 \%$ & $2.5 \%$ & $2.5 \%$ \\
\hline \multicolumn{2}{|c|}{ Total } & $\begin{array}{c}40 \\
100.0 \%\end{array}$ & $\begin{array}{c}40 \\
100.0 \%\end{array}$ & $\begin{array}{c}80 \\
100.0 \%\end{array}$ \\
\hline \multicolumn{5}{|c|}{$\begin{array}{c}\text { Table 2. I-gel Insertion Grading by } \\
\text { Anaesthesiologist }\end{array}$} \\
\hline
\end{tabular}

Parameter: MAP

\begin{tabular}{|c|c|c|c|c|c|c|c|}
\hline & Group & $\mathbf{N}$ & Mean & Std. Deviation & Median & T value & P value \\
\hline \multirow{2}{*}{ Baseline } & Group A & 40 & 76.08 & 21.405 & 75.00 & \multirow{2}{*}{1.94} & \multirow{2}{*}{.058} \\
\hline & Group B & 40 & 83.00 & 7.232 & 87.00 & & \\
\hline \multirow{2}{*}{ BI } & Group A & 40 & 93.23 & 12.065 & 91.50 & \multirow{2}{*}{4.77} & \multirow[t]{2}{*}{.000} \\
\hline & Group B & 40 & 79.58 & 13.485 & 82.00 & & \\
\hline \multirow{2}{*}{$\mathrm{AI}$} & Group A & 40 & 88.30 & 12.047 & 90.50 & \multirow{2}{*}{4.00} & \multirow[t]{2}{*}{.000} \\
\hline & Group B & 40 & 79.48 & 7.075 & 80.00 & & \\
\hline \multirow{2}{*}{1 Min. } & Group A & 40 & 82.60 & 13.958 & 85.00 & \multirow{2}{*}{2.38} & \multirow[t]{2}{*}{.020} \\
\hline & Group B & 40 & 76.60 & 7.652 & 76.00 & & \\
\hline \multirow{2}{*}{2 Min. } & Group A & 40 & 80.48 & 11.953 & 80.00 & \multirow{2}{*}{2.94} & .004 \\
\hline & Group B & 40 & 73.95 & 7.366 & 73.00 & & Hs \\
\hline \multirow{2}{*}{3 Min. } & Group A & 40 & 76.85 & 13.012 & 78.00 & \multirow{2}{*}{2.32} & .023 \\
\hline & Group B & 40 & 71.28 & 7.897 & 70.00 & & Sig \\
\hline \multirow{2}{*}{5 Min. } & Group A & 40 & 73.78 & 12.255 & 74.50 & \multirow{2}{*}{1.29} & \multirow{2}{*}{.200} \\
\hline & Group B & 40 & 70.58 & 9.771 & 70.00 & & \\
\hline \multirow{2}{*}{10 Min. } & Group A & 40 & 71.48 & 11.649 & 70.50 & \multirow{2}{*}{1.06} & \multirow{2}{*}{.294} \\
\hline & Group B & 40 & 69.05 & 8.685 & 68.50 & & \\
\hline \multirow{2}{*}{15 Min. } & Group A & 40 & 69.30 & 11.248 & 69.00 & \multirow{2}{*}{.21} & \multirow{2}{*}{.833} \\
\hline & Group B & 40 & 68.80 & 9.890 & 67.00 & & \\
\hline & & & $T a$ & Arterial $P$ & & & \\
\hline
\end{tabular}

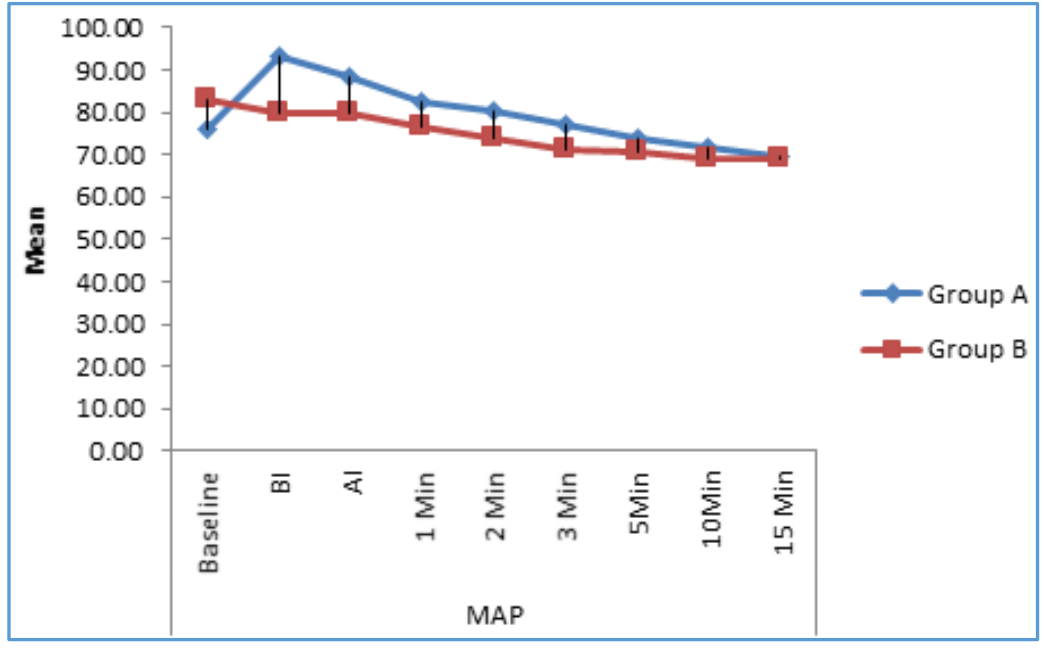


Parameter: Heart rate

\begin{tabular}{|c|c|c|c|c|c|c|c|}
\hline & Group & $\mathbf{N}$ & Mean & Std. Deviation & Median & T value & P value \\
\hline \multirow{2}{*}{ Baseline } & Group A & 40 & 77.28 & 12.318 & 74.50 & \multirow{2}{*}{.23} & \multirow{2}{*}{.822} \\
\hline & Group B & 40 & 78.03 & 17.050 & 78.00 & & \\
\hline \multirow{2}{*}{ BI } & Group A & 40 & 77.60 & 11.683 & 75.50 & \multirow{2}{*}{.26} & \multirow{2}{*}{.797} \\
\hline & Group B & 40 & 76.80 & 15.732 & 77.00 & & \\
\hline \multirow{2}{*}{ AI } & Group A & 40 & 74.75 & 13.511 & 72.50 & \multirow{2}{*}{.02} & \multirow{2}{*}{.988} \\
\hline & Group B & 40 & 74.80 & 15.604 & 74.50 & & \\
\hline \multirow{2}{*}{$1 \mathrm{Min}}$. & Group A & 40 & 73.58 & 14.071 & 70.00 & \multirow{2}{*}{.19} & \multirow{2}{*}{.853} \\
\hline & Group B & 40 & 72.98 & 14.883 & 74.00 & & \\
\hline \multirow{2}{*}{2 Min. } & Group A & 40 & 70.83 & 14.066 & 66.00 & \multirow{2}{*}{.20} & \multirow{2}{*}{.845} \\
\hline & Group B & 40 & 71.45 & 14.443 & 74.00 & & \\
\hline \multirow{2}{*}{3 Min. } & Group A & 40 & 68.58 & 13.574 & 65.00 & \multirow{2}{*}{.51} & \multirow{2}{*}{.611} \\
\hline & Group B & 40 & 70.20 & 14.874 & 72.00 & & \\
\hline \multirow{2}{*}{5 Min. } & Group A & 40 & 66.38 & 13.707 & 62.50 & \multirow{2}{*}{1.12} & \multirow{2}{*}{.267} \\
\hline & Group B & 40 & 69.85 & 14.065 & 71.00 & & \\
\hline \multirow{2}{*}{10 Min. } & Group A & 40 & 63.98 & 13.360 & 60.50 & \multirow{2}{*}{1.68} & \multirow{2}{*}{.097} \\
\hline & Group B & 40 & 69.08 & 13.811 & 70.00 & & \\
\hline \multirow{2}{*}{15 Min. } & Group A & 40 & 60.05 & 14.240 & 58.00 & \multirow{2}{*}{2.61} & \multirow{2}{*}{ Sig } \\
\hline & Group B & 40 & 68.35 & 14.208 & 70.00 & & \\
\hline \multicolumn{8}{|c|}{ Table 3. Mean Arterial Pressure } \\
\hline
\end{tabular}

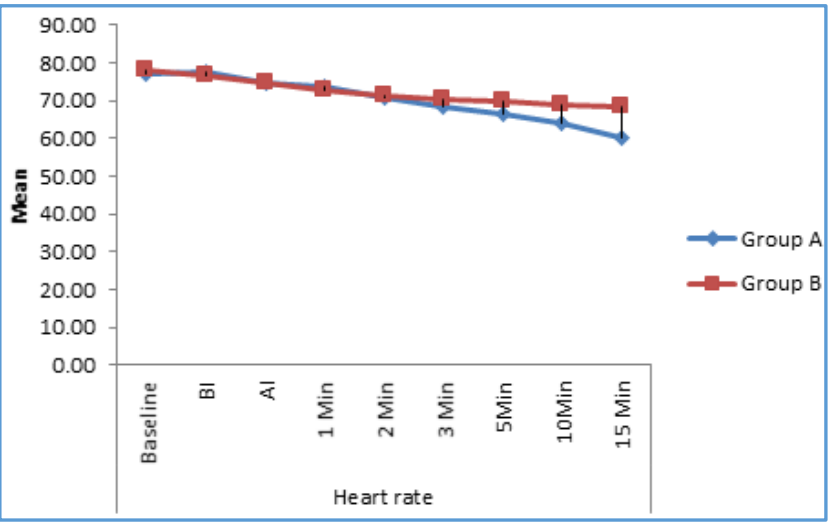

\section{DISCUSSION}

Supralaryngeal devices are used commonly in anaesthetic practice. Here, in our study, we have used I-gel and comparison of I-gel insertion using dexmedetomidine in one group and fentanyl in other group following induction with propofol.

We have compared the performance of I-gel using 1 $\mathrm{mcg} / \mathrm{kg}$ of dexmedetomidine over $10 \mathrm{~min}$. IV along with 2 $\mathrm{mg} / \mathrm{kg}$ of propofol or with $1 \mathrm{mcg} / \mathrm{kg}$ fentanyl with $2 \mathrm{mg} / \mathrm{kg}$ propofol. High success rate for insertion of I-gel was possible in one or two attempts in both the groups with subsequent adequate ventilation.

Successful insertion was established in 33/40 (82.5\%) in group A and 37/40 (92.5 \%) in group B on first attempt and remaining patients on second attempt. No participant has taken more than two attempts. There was statistically no significant success rate of first attempt insertion in both the groups $(\mathrm{p}=0.500)$.

N. M. Wharton et al evaluated the performance of I-gel in manikins and forty healthy anaesthetised patients when used by novices, success on first attempt was 33/40 patients $(82.5 \%)$ and second attempt $6 / 40(15 \%) .{ }^{5}$

J. J. Gatward et al evaluated I-gel insertion in hundred non paralysed patients with propofol induction. First attempt success was achieved in 86/100 (86\%), second attempt in $11 / 100(11 \%)$ and third attempt in $3 / 100(3 \%){ }^{6}$

Ishwar Singh et al compared clinical performance of I-gel with LMA ProSeal in elective surgeries. The success rate at first

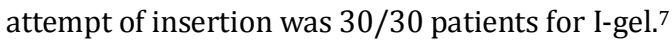

H. Francksen et al compared I-gel and LMA Unique insertion in 80 non-paralysed and anaesthetised patients with propofol induction. Primary airway was established in 36/40 (90\%) on the first attempt and $4 / 40(10 \%)$ on the second attempt in I-gel group. ${ }^{8}$

Our results were comparable with above studies. We have studied patients' response to I-gel insertion as excellent, good, poor, depending upon incidence of gagging, stridor, laryngospasm, requirement of additional inhalational agent, need of increasing depth of anaesthesia. Response was excellent $40 / 40(100 \%)$ in group A and excellent 40/40 (100\%) in group B as well. No statistical significant difference noted in both the groups.

L. Theiler, M. Gutzmann et al conducted study in 5 different hospitals in Switzerland over 24 months in patients posted for elective surgical procedures, and they have observed that adverse events noted were $1.2 \%$ laryngeal spasms, 3.9\% blood stain on device and one with glottic haematoma. ${ }^{9}$

Ashish Kannaujia, Uma Srivastava et al conducted studies in 50 patients of ASA I-III class and they have noticed that increasing depth of anaesthesia was needed in $8 \%$ of the patients and no other significant adverse effects noted in the perioperative period. 10

I-gel insertion was graded by anaesthesiologist based on ease of I-gel insertion as easy a, very easy or difficult. It was found that I-gel insertion was easy in 39/40 (97.5\%) and very easy in $1 / 39$ (2.5 \%) in group A. In group B insertion was easy in $39 / 40(97.5 \%)$ and very easy in $1 / 40(2.5 \%)$. There was statistically no significant difference in between two groups.

L. Theiler, M. Gutzmann et al conducted studies in 5 different hospitals in Switzerland over 24 months in patients posted for elective surgical procedures and they have found out that 
insertion of I-gel was easy or very easy in $92.5 \%$ of the patients. ${ }^{9}$

Ashish Kannaujia, Uma Srivastava et al conducted studies in 50 patients of ASA I-III class and they have found out that insertion of I-gel was easy with $90 \%$ in first attempt and $10 \%$ needed second attempt. 10

Our results were comparable with the above studies. ${ }^{10}$ Our results were comparable with the studies done earlier.

Comparison of haemodynamic changes between the two groups revealed that there was decrease in mean heart rate in both the groups after induction and significant fall in mean heart rate noted in group $A$ at the end of $15 \min (p=0.011)$. There was significant decrease in mean blood pressure in group A compared to group B pressure at $1 \mathrm{~min}$., $2 \mathrm{~min}$., $3 \mathrm{~min}$., $5 \mathrm{~min}$. and at $10 \mathrm{~min}$. (p=.037). But at end of $15 \mathrm{~min}$., it was not statistically significant $(\mathrm{p}=0.092)$.

In a study by A Sowmya Jayaram, P Janaki Subhadra et al in 2014 done on 60 patients for comparison of dexmedetomidine-propofol versus fentanyl-propofol for condition of LMA insertion in elective surgeries, it was concluded that dexmedetomidine gives better insertion condition and better attenuation of pressor response compared to fentanyl.

In a randomised double blind trial by Suparto, Olivia C Flores et al, 2010, involving 56 patients who were allocated to two groups, received either $1 \mathrm{mcg} / \mathrm{kg}$ of dexmedetomidine or fentanyl $1 \mathrm{mcg} / \mathrm{kg}$ prior to induction, followed by propofol and maintained on 02-sevoflurane. Intraop haemodynamic parameters were noted and it was concluded that both groups showed decrease in blood pressure and mean heart rate but significant decrease in mean heart rate noted in dexmedetomidine group. Laryngoscopy and intubation showed less increase in heart rate and blood pressure in dexmedetomidine group. ${ }^{11}$

A study by Sellamuthu Gunalan, Rajagopalan Venkatraman et al in 2015, including 60 patients posted for elective surgical procedure who were divided into two groups; one group was given $1 \mathrm{mcg} / \mathrm{kg}$ dexmedetomidine and other $1 \mathrm{mcg} / \mathrm{kg}$ of fentanyl before induction. Anaesthesia was standardised and vitals were noted. It was concluded that attenuation of heart rate and blood pressure was more with dexmedetomidine than fentanyl.12

Our results were comparable to that of above studies with respect to haemodynamic response.

In the present study, airway complications such as $\mathrm{SpO} 2$ $<95 \%$, regurgitation, aspiration, blood stain on I-gel were not seen in any of the groups.

Low incidence of airway complications could be due to high success rate of first attempt insertion.

Gatward J J et al reported one episode of regurgitation but without aspiration. Other complications and side effects were very mild and very few. ${ }^{6}$

Wharton $\mathrm{N} \mathrm{W}$ et al reported one case of aspiration and partial regurgitation out of 40 healthy anaesthetised patients. ${ }^{5}$

\section{CONCLUSIONS}

Propofol induction with dexmedetomidine and with fentanyl provides ideal conditions for insertion of I-gel.

We have obtained similar insertion conditions in both the groups with no adverse effects.

We conclude that both dexmedetomidine and fentanyl with propofol provide ideal conditions for I-gel insertion with more attenuation of haemodynamic response in dexmedetomidine group compared to fentanyl group.

\section{REFERENCES}

1. Das A, Majumdar S, Mukherjee A, et al. I-gel ${ }^{\mathrm{TM}}$ in ambulatory surgery: a comparison with LMA-ProSealTM in paralyzed anaesthetized patients. J Clin Diagnostic Res 2014;8(3):80-4.

2. Pournajafian A, Alimian M, Rokhtabnak F, et al. Success rate of airway devices insertion: laryngeal mask airway versus supraglottic gel device. Anesthesiol pain Med 2015;5(2):e22068.

3. Ramaswamy AH, Shaikh SI. Comparison of dexmedetomidine-propofol versus fentanyl-propofol for insertion of laryngeal mask airway. J Anaesthesiol Clin Pharmacol 2015;31(2):217-20.

4. Kodaka M, Okamoto Y, Handa F, et al. Relation between fentanyl dose and predicted EC50 of propofol for laryngeal mask insertion. British Journal of Anaesthesia 2004;92(2):238-41.

5. Wharton NM, Gibbison B, Gabbott DA, et al. I-gel insertion by novices in manikins and patients. Anaesthesia 2008;63(9):991-5.

6. Gatward JJ, Cook TM, Seller C, et al. Evaluation of the size 4 I-gel airway in one hundred non-paralysed patients. Anaesthesia 2008;63(10):1124-30.

7. Najeeb R, Saini H, Ommid M, et al. Comparison of I-gel, ProSeal LMA and endotracheal tube in laparoscopic surgeries. IOSR J Dent Med Sci 2015;14(6):2279-861.

8. Francksen H, Renner J, Hanss R, et al. A comparison of the i-gel with the LMA-Unique in non-paralysed anaesthetised adult patients. Anaesthesia 2009;64(10):1118-24.

9. Theiler L, Gutzmann M, Kleine-Brueggeney M, et al. I-gel ${ }^{\mathrm{TM}}$ supraglottic airway in clinical practice: a prospective observational multicentre study. $\mathrm{Br} J$ Anaesth 2012;109(6):990-5.

10. Kannaujia A, Srivastava U, Saraswat N, et al. A preliminary study of I-gel: a new supraglottic airway device. Indian J Anaesth 2009;53(1):52-6.

11. Flores OC, Layusa CAA. A randomized controlled trial on the effectiveness of dexmedetomidine versus fentanyl in attenuating the sympathetic response to direct laryngoscopy and endotracheal intubation. Maj Kedokt Indon 2010;60(3):126-33.

12. Gunalan S, Venkatraman R, Sivarajan G, et al. Comparative evaluation of bolus administration of dexmedetomidine and fentanyl for stress attenuation during laryngoscopy and endotracheal intubation. J Clin Diagnostic Res 2015;9(9):UC06-UC09. 